\title{
Fatty Liver Index and Serum Copeptin as Early Predictors of Gestational Diabetes Mellitus in Non-diabetic Pregnant Women
}

\author{
Haitham Hamza, MD* \\ Department of Obstetrics and Gynecology, Faculty of Medicine, Menoufia University, Menoufia governorate, \\ Egypt
}

*Corresponding Author: Haitham Hamza, MD, Department of Obstetrics and Gynecology, Faculty of Medicine, 25Yasin Abd-Elghafar street, Shibin Elkom city, Menoufia University, Menoufia governorate, Egypt, Email: egysmart80@gmail.com

\begin{abstract}
Objectives: To evaluate value of determination of fatty liver disease (FLD) and estimation of serum co-peptin $(C P)$ at the $6^{\text {th }}$ gestational week $(G W)$ as early predictors for development of gestational diabetes mellitus (GDM) later on during pregnancy in non-diabetic pregnant women.
\end{abstract}

Methods: The study included 385 pregnant women at the $6^{\text {th }} \mathrm{GW}$ for clinical evaluation, determination of body mass index (BMI) and waist circumference and gave blood samples for estimation of serum triglyceride (TG), $\gamma$-glutamyl transferase (GGT) insulin and CP and underwent the 75-oral glucose tolerance test (75OGTT). Fatty liver index and homeostasis model assessment of IR (HOMA-IR) were calculated. At the $24^{\text {th }}$ GW, 75-OGTT and serum insulin were re-evaluated and women developed GDM were collected as GDM group and women who were free of GDM till the $24^{\text {th }} \mathrm{GW}$ as control group.

Results: At $24^{\text {th }} G W$, all studied women had higher blood glucose, serum insulin, TG and GGT with increased HOMA-IR and FLI scores in comparison to $6^{\text {th }} G W$ measures. The increase was non-significant in 338 women (controls) and was significant in 47 women (GDM group) who showed significantly higher measures compared to controls for a frequency of GDM of $12.2 \%$. At $6^{\text {th }} \mathrm{GW}$ serum CP levels were significantly higher in GDM than in control women. Statistical analyses defined high FLI and serum CP at the $6^{\text {th }} G W$ as significant predictors for subsequent development of GDM.

Conclusion: Development of GDM is closely associated with pregnancy-induced IR and is more frequent in women who had FLD. Increased serum CP levels may be concomitant event or underlying cause for GDM. Calculation of FLI at the $6^{\text {th }} G W$ could discriminate women at risk for GDM later during pregnancy especially if associated with high serum CP levels.

Keywords: Fatty liver index, Co-peptin, Insulin resistance, Gestational diabetes mellitus

\section{INTRODUCTION}

The body responses to metabolic demands of pregnancy still a challenging concern for physicians [1] and became a stressful target with the global increasing prevalence of obesity [2]. During pregnancy glucose metabolism is governed by equilibrium between lactogenic hormones stimulating insulin production and counter-regulatory hormones inducing insulin resistance (IR) [3].

Multiple peptides play a major role in pathogenesis of metabolic disorders [4] and substances of hormonal character secreted by adipose tissue (Adipokines) are of great importance for carbohydrate metabolism [5]. Multiple studies documented disturbed

ARC Journal of Gynecology and Obstetrics adipokines levels early in pregnancy among women who later develop GDM than women completed their pregnancy free of GDM [6].

Copeptin (CP), a 39-aminoacid glycopeptide, is the $\mathrm{COOH}$-terminal portion of the precursor pre-pro-vasopressin [7]. Activation of the Arginine vasopressin (AVP) system stimulates $\mathrm{CP}$ secretion into the circulation from the posterior pituitary gland in equimolar amounts with AVP [8]. Therefore, CP directly reflects AVP concentration and can be used as a surrogate biomarker of AVP secretion [9].

Fatty liver disease (FLD) is one of the most frequent liver diseases and includes nonalcoholic and alcoholic FLD, each of which is increasing in prevalence [10]. Obesity and its 
complications, especially type 2 diabetes mellitus (DM) and hyper-triglyceridemia, are the main responsible factors for the development of the epidemic of FLD [11]. Body mass index (BMI) is a surrogate index of body adiposity and a strong risk factor for FLD [12]. Waist circumference was hypothesized to be a predictor of FLD independently from BMI [13].

Imaging procedures and liver biopsy are the most common methods used for FLD diagnosis, but no single procedure was reliable enough [14] and liver biopsy, despite being the gold standard, it is invasive and expensive tool and has some health risks [15]. A number of indices that consist of simple measures were introduced to diagnose FLD [16]. Fatty liver index (FLI) is one of these indices developed as a convenient tool based on BMI, waist circumference (WC), triglyceride (TG), and gamma glutamyl transferase (GGT) levels [17, 18].

The current study tried to evaluate the validity of determination of FLD and estimation of serum $\mathrm{CP}$ at the 6th gestational week $(\mathrm{GW})$ as early predictors for development of gestational DM (GDM) later on during pregnancy in nondiabetic pregnant women.

\section{Materials AND Methods}

\subsection{Setting}

Departments of Obstetrics \& Gynecology and Clinical Pathology, Menufia University hospitals, Menoufia governorate, Egypt

\subsection{Design}

Prospective Observational Study

\subsection{Methodology}

The study was started since Aug 2015 till December 2018; the study protocol was approved by the Local Ethical Committee and only couples signed a written fully informed consent were included in the study. All pregnant women who attended the Antenatal Outpatient Clinics (OPC), Menufia University hospital; for assurance of diagnosis of being pregnant were eligible for study inclusion.

At the $6^{\text {th }} \mathrm{GW}$, women's demographic and clinical data were collected. Then, waist circumference was determined twice and the median of both measurements was obtained. Body weight and height were determined for calculation of BMI in $\mathrm{kg} / \mathrm{m}^{2}$ as weight $(\mathrm{kg}) /$ height $\left(\mathrm{m}^{2}\right)$ and patients were classified according to BMI using the World Health Organization ranges [19].
Baseline clinical and obstetric data were collected and verified to assure inclusion and exclusion criteria.

Exclusion criteria included pre-pregnancy DM, history of previous GDM, essential hypertension, previous exposure to hepatotoxins, positive serum testing for hepatitis $\mathrm{B}$ or $\mathrm{C}$, hepatic masses, gall bladder or biliary tree diseases. Women lost during the course of pregnancy were excluded.

At the $6^{\text {th }} \mathrm{GW}$, all women were asked to attend the OPC next day fasting for 18 hours to give blood samples to determine baseline fasting blood glucose (FBG), triglycerides and serum levels of CP, insulin, $\gamma$-glutamyl transferase, and to undergo the 75-OGTT. The 75-OGTT entails obtaining three blood samples; a fasting sample and two samples 1-hr and 2-hrs after taking an oral snack containing $75 \mathrm{gm}$ glucose for estimation of postprandial blood glucose (PPBG). All women underwent abdominal ultrasonongraphy to determine the presence of fatty liver. At the $24^{\text {th }} \mathrm{GW}$, women were asked to attend after overnight fasting to the OPC to give blood sample for re-estimation of serum insulin and undergo the 75-OGTT. The study plan was to include pregnant women who developed GDM at the $24^{\text {th }}$ week visit as GDM group and women who were free of GDM till the $24^{\text {th }} \mathrm{GW}$ as control group.

\subsection{Investigations}

\subsubsection{Sampling}

Venous blood samples $(5 \mathrm{ml})$ were collected from the antecubital vein under complete aseptic conditions and were divided into two parts:

1. The first part was put in a tube containing sodium fluoride (2 $\mathrm{mg}$ sodium fluoride/ $\mathrm{ml}$ blood) to prevent glycolysis and plasma was separated by centrifugation to be used for estimation of blood glucose levels, at hospital lab.

2. The second part was collected in plain tube, allowed to clot, centrifuged at $1500 \times \mathrm{g}$ for $15 \mathrm{~min}$ and the serum was divided into two parts; one was used for immediate estimation of serum GGT and TG (at hospital lab) and the second part was collected in clean dry Eppendorf tube to be stored at $-70^{\circ} \mathrm{C}$ until assayed.

\subsubsection{Laboratory Investigations}

Serum levels of insulin and $\mathrm{CP}$ were measured using enzyme linked immunosorbent assay (ELISA) kits according to the manufacturer's 
Fatty Liver Index and Serum Copeptin as Early Predictors of Gestational Diabetes Mellitus in Nondiabetic Pregnant Women

instructions and were read using a 96 well microplate ELISA reader (Dynatech MR 7000).

1. Human insulin was measured with the enzyme linked immunoassay (ELISA) kit (catalogue no. ab200011, Abcam Inc., Cambridge, UK) by quantitative sandwich enzyme immunoassay technique [20].

2. Human $\mathrm{CP}$ was measured with the enzyme linked immunoassay (ELISA) kit (catalogue no. MBS703328, MyBioSource, Inc., California, San Diego, USA) by quantitative sandwich enzyme immunoassay technique [21].

\subsubsection{Clinical Parameters}

1. Insulin resistance (IR) was evaluated using the homeostasis model assessment of IR (HOMA-IR) on the basis of insulin and glucose levels and according to the formula fasting serum insulin $(\mu \mathrm{U} / \mathrm{ml}) \times$ [fasting plasma glucose $(\mathrm{mg} / \mathrm{ml}) / 18]) / 22.5$; HOMAIR score of $>2$ is considered abnormal [22].

2. GDM was defined according to the American Diabetes Association [23] as the first recognition of any degree of glucose intolerance during pregnancy and determined according to the results of the Hyperglycemia and Adverse Pregnancy
Outcome (HAPO) study [24] and International association of diabetes and pregnancy study groups recommendations [25] as follows: FBG $\geq 92 \mathrm{mg} / \mathrm{dl}, 1-\mathrm{h} \mathrm{BG}$ $\geq 180 \mathrm{mg} / \mathrm{dl}$ and $2-\mathrm{h} \mathrm{BG} \geq 153 \mathrm{mg} / \mathrm{dl}$.

3. Fatty liver index (FLI) calculated by using 4 variables: BMI $\left(\mathrm{kg} / \mathrm{m}^{2}\right)$, waist circumference $(\mathrm{cm})$, TG $(\mathrm{mg} / \mathrm{ml})$, and GGT $(\mathrm{U} / \mathrm{L})$ and ranges from 0 to 100 . A FLI value $<30$ rules out FL, so needs no intervention, while FLI value $\geq 60$ indicates $\mathrm{FL}$ that needs therapy and in between is the grey zone that can be adjusted by lifestyle change and dieting regimen (17).

\section{RESULTS}

Through duration of the study, 412 pregnant women were eligible for evaluation; 27 were excluded for not fulfilling inclusion criteria and 385 women were enrolled in the study. At the $24^{\text {th }} \mathrm{GW}, 47$ women developed GDM (GDM group) for a frequency of $12.2 \%$. Patients enrolment data concerning age, gravidity and parity and at enrolment blood pressure measures showed non-significant ( $p>0.05)$ difference between women developed GDM and women continued their pregnancy free of DM (Control group).

Table1. Patients' data determined at time of enrolment

\begin{tabular}{|c|c|c|c|c|}
\hline \multicolumn{2}{|l|}{ Data } & Control group $(n=338)$ & GDM group $(n=47)$ & P value \\
\hline \multicolumn{2}{|c|}{ Age (years) } & $28.3 \pm 3.5$ & $29.1 \pm 4.6$ & 0.362 \\
\hline \multicolumn{2}{|c|}{ Gravidity } & $2.3 \pm 1.1$ & $1.9 \pm 0.8$ & 0.093 \\
\hline \multicolumn{2}{|c|}{ Parity } & $1.2 \pm 0.8$ & $1 \pm 0.6$ & 0.286 \\
\hline \multirow{2}{*}{$\begin{array}{l}\text { Blood } \\
\text { pressure }\end{array}$} & Systolic & $114.6 \pm 9.7$ & $116.5 \pm 7.9$ & 0.582 \\
\hline & Diastolic & $74.9 \pm 5.9$ & $78 \pm 6.1$ & 0.783 \\
\hline \multicolumn{2}{|c|}{ Fasting blood glucose $(\mathrm{mg} / \mathrm{dl})$} & $84.7 \pm 11.4$ & $87.1 \pm 14.9$ & 0.541 \\
\hline
\end{tabular}

Data are presented as mean $\pm S D$; $p$ indicates significance of difference between both groups; $p>0.05$ : indicates non-significant difference

Mean FBG, 2-hr PPBG and serum insulin estimated at the $6^{\text {th }} \mathrm{GW}$ were non-significantly higher in GDM versus control women. All women had increased blood glucose and serum insulin levels at the $24^{\text {th }} \mathrm{GW}$; however, the difference, in comparison to levels estimated at the $6^{\text {th }} \mathrm{GW}$, was non-significant $(\mathrm{p}>0.05)$ in control, but was significant in GDM women with significantly higher estimates compared to control women (Table 2).

Table2. Laboratory data of women of studied groups

\begin{tabular}{|l|l|c|c|c|}
\hline Variable & Time & Control group $(\mathbf{n = 3 3 8})$ & GDM group $(\mathbf{n}=47)$ & P value \\
\hline \multirow{2}{*}{ FBG $(\mathrm{mg} / \mathrm{dl})$} & At $6^{\text {th }} \mathrm{WG}$ & $92.7 \pm 13.6$ & $94.9 \pm 16.5$ & 0.122 \\
\cline { 2 - 5 } & At $24^{\text {th }} \mathrm{WG}$ & $93.5 \pm 6.8$ & $107.9 \pm 9.9^{*}$ & $<0.001$ \\
\hline \multirow{2}{*}{ S-hr PPBG $(\mathrm{mg} / \mathrm{dl})$} & At $6^{\text {th }} \mathrm{WG}$ & $115.8 \pm 11.7$ & $119.1 \pm 7.5$ & 0.342 \\
\cline { 2 - 5 } & At $24^{\text {th }} \mathrm{WG}$ & $118.5 \pm 13.1$ & $193.7 \pm 19^{*}$ & $<0.001$ \\
\hline \multirow{2}{*}{ Serum insulin } & At $6^{\text {th }} \mathrm{WG}$ & $7.4 \pm 3.6$ & $8.3 \pm 5.2$ & 0.069 \\
\cline { 2 - 5 } & At $24^{\text {th }} \mathrm{WG}$ & $8.2 \pm 4.7$ & $12.5 \pm 4.3^{*}$ & $<0.001$ \\
\hline
\end{tabular}

Data are presented as mean $\pm S D ; p$ indicates significance of difference between both groups; *: indicates significant difference versus at $6^{\text {th }} G W$ estimates; $p>0.05$ : indicates non-significant difference

According to BMI calculated at the $6^{\text {th }} \mathrm{GW}$ (time of enrolment), 89 women were obese, 221 women were overweight and only 75 women had average weight with significantly higher 
Fatty Liver Index and Serum Copeptin as Early Predictors of Gestational Diabetes Mellitus in Nondiabetic Pregnant Women

$(\mathrm{p}<0.001)$ frequency of obese women among GDM group. Moreover, mean BMI was significantly higher in GDM versus control groups. HOMA-IR score calculated at the $6^{\text {th }}$ GW defined 92 insulin resistant women with HOMA-IR score of $\geq 2$, while 293 women had HOMA-IR score of $<2$. According to calculated FLI 69 women had fatty liver with FLI score $>60$, only 89 control women were rules out

Table3. Clinical scores of studied women determined at time of enrolment

\begin{tabular}{|c|c|c|c|c|c|}
\hline \multicolumn{3}{|l|}{ Data } & Control group $(n=338)$ & GDM group $(n=47)$ & $P$ value \\
\hline \multirow[t]{4}{*}{$\mathrm{BMI}\left(\mathrm{Kg} / \mathrm{m}^{2}\right)$} & \multirow[t]{3}{*}{ Frequency } & $<25$ & $73(21.6 \%)$ & $2(4.3 \%)$ & \multirow{3}{*}{$<0.001$} \\
\hline & & $25-30$ & $202(59.8 \%)$ & $19(40.4 \%)$ & \\
\hline & & $>30$ & $63(18.6 \%)$ & $26(55.3 \%)$ & \\
\hline & \multicolumn{2}{|l|}{ Mean } & $28 \pm 2.9$ & $30.3 \pm 2.4$ & $<0.001$ \\
\hline \multirow[t]{3}{*}{ HOMA-IR } & \multirow[t]{2}{*}{ Frequency } & $<2$ & $268(79.3 \%)$ & $25(53.2 \%)$ & \multirow{2}{*}{$<0.001$} \\
\hline & & $\geq 2$ & $70(20.7 \%)$ & $22(46.8 \%)$ & \\
\hline & \multicolumn{2}{|l|}{ Mean } & $1.73 \pm 0.51$ & $2 \pm 0.54$ & $<0.001$ \\
\hline \multirow[t]{4}{*}{ FLI } & \multirow[t]{3}{*}{ Frequency } & $>60$ & $169.6 \pm 3.4$ & $169.9 \pm 3.1$ & \multirow{3}{*}{$<0.001$} \\
\hline & & $30-60$ & $28.3 \pm 3$ & $29.6 \pm 2.7$ & \\
\hline & & $<30$ & $2 \pm 0.8$ & $1.7 \pm 0.7$ & \\
\hline & \multicolumn{2}{|l|}{ Mean } & $43.3 \pm 14.1$ & $71.4 \pm 13.1$ & $<0.001$ \\
\hline
\end{tabular}

Data are presented as mean $\pm S D$, numbers \& percentages; BMI: Body mass index; HOMA-IR: Homeostasis model assessment of insulin resistance; FLI: Fatty liver index; $p$ indicates significance between both groups; $p<0.05$ : indicates significant difference

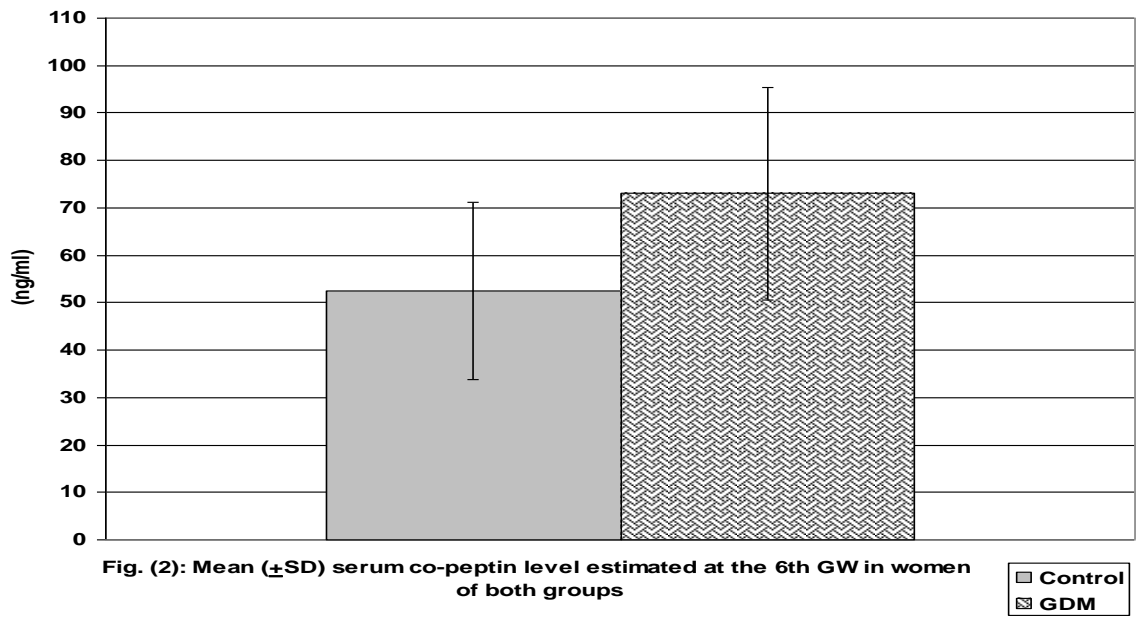

Development of GDM at the $24^{\text {th }} \mathrm{GW}$ positively correlated with FLI, serum CP, BMI and HOMA-IR score determined at the $6^{\text {th }} \mathrm{GW}$, in decreasing order of significance and ROC curve analysis considered these four variables as positive early predictors for later development of GDM, in the same decreasing order of significance (Fig. 3). Regression analysis defined at $6^{\text {th }}$ GW high FLI and serum $\mathrm{CP}$ as early predictors for development of GDM at the $24^{\text {th }} \mathrm{GW}$ (Table 4 ).

Table4. Statistical analyses for variables determined at the $6^{\text {th }} G W$ as early predictors for later development of $G D M$

\begin{tabular}{|l|l|l|l|l|l|l|}
\hline \multirow{2}{*}{ Variable } & \multicolumn{2}{l|l}{ Correlation } & \multicolumn{2}{l|}{ ROC curve analysis } & Regression analysis \\
\cline { 2 - 8 } & $\mathrm{r}$ & $\mathrm{p}$ & $\mathrm{AUC}(95 \% \mathrm{CI})$ & $\beta$ & $\mathrm{p}$ \\
\hline BMI & 0.233 & $<0.001$ & $0.745(0.677-0.813)$ & $<0.001$ & 0.011 & 0.030 \\
\hline HOMA-IR & 0.175 & 0.001 & $0.656(0.569-0.743)$ & 0.001 & 0.130 & 0.002 \\
\hline FLI & 0.548 & $<0.001$ & $0.903(0.855-0.950)$ & $<0.001$ & 0.557 & $<0.001$ \\
\hline Serum CP & 0.345 & $<0.001$ & $0.775(0.710-0.840)$ & $<0.001$ & 0.222 & $<0.001$ \\
\hline
\end{tabular}

BMI: Body mass index; HOMA-IR: Homeostasis model assessment of insulin resistance; FLI: Fatty liver index; CP: Co-peptin; $p$ indicates significance of calculated value; $p<0.05$ : indicates significant difference 
Fatty Liver Index and Serum Copeptin as Early Predictors of Gestational Diabetes Mellitus in Nondiabetic Pregnant Women


Figure3. ROC curve analysis of variables determined at the $6^{\text {th }} G W$ as early predictors for later development of GDM

Kaplan-Meier regression analysis of calculated FLI defined value of 77.75 (95\% CI: 75.8-79.7) and mean serum at $90.96 \mathrm{mg} / \mathrm{ml}(95 \% \mathrm{CI}$ :
85.59-96.32) as cutoff points beyond which the hazard for development of GDM increases sharply (Fig. 4 \& 5).

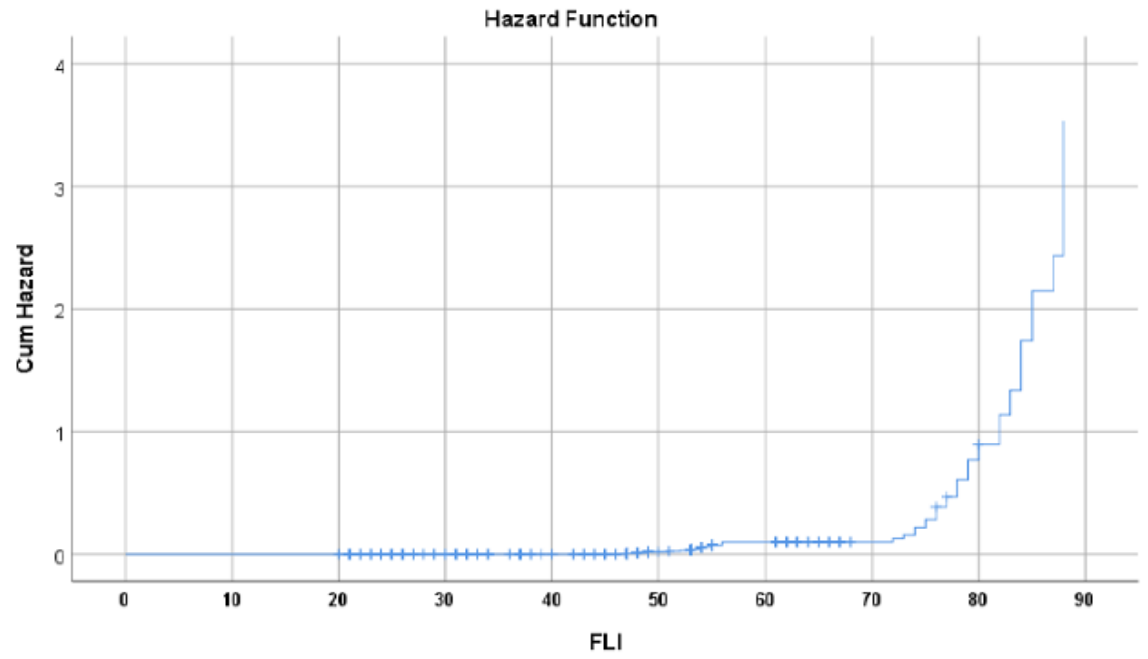

Figure4. Kaplan-Meier regression analysis for calculated FLI to defined FLI= 77.75 as a cutoff point above which the hazard for getting GDM increases sharply

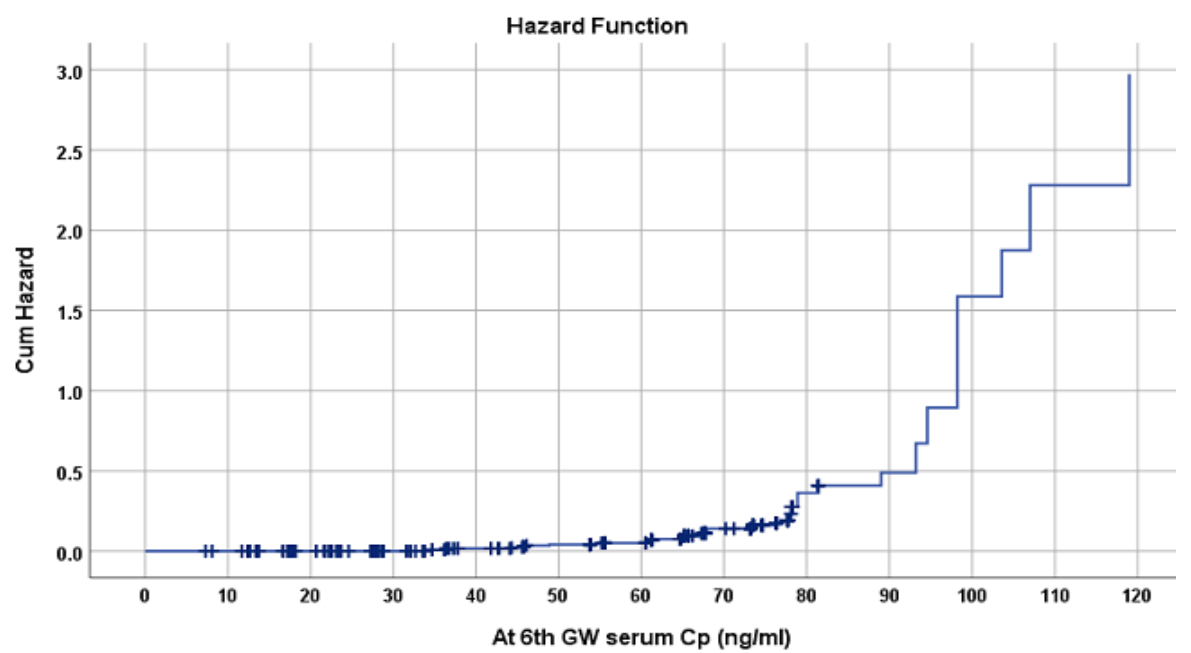

Figure5. Kaplan-Meier regression analysis for at 6th $G W$ estimated serum CP level defined CP level at FLI= $90.98 \mathrm{mg} / \mathrm{ml}$ as a cutoff point above which the hazard for getting GDM increases sharply 


\section{DISCUSSION}

At the $24^{\text {th }} \mathrm{GW}$, all women showed increased blood glucose measures, serum insulin, TG and GGT with subsequent increased HOMA-IR and FLI scores in comparison to $6^{\text {th }} \mathrm{GW}$ measures, but the increase was non-significant in 338 women (controls) and was significant in 47 women (GDM group) who showed significantly higher measures compared to controls for a frequency of GDM of $12.2 \%$ among nondiabetic pregnant women. These data are in accordance with Lacaria et al. [26] and Du et al. [27] who reported prevalence rates of GDM of $10.9 \%$ and $8.5 \%$, respectively. Through the current study, diagnosis of GDM relied on IADPSG criteria; similarly Sacks et al. [28] reported that among centers that participated in HAPO Study the frequency of GDM had ranged between 9.3 and $25.5 \%$ using the IADPSG criteria and Waters et al. [29] out of metaanalysis found $14.3 \%$ of studied pregnant women had GDM defined according to IADPSG criteria.

The obtained results are in line with Layton et al. [30] who found women with GDM are characterized by a predominant insulin sensitivity defect than women with normal glucose tolerance and Wang et al. [31] documented that GDM recurred in more than half of subsequent pregnancies and women who had lower FPG and higher 1-h PPBG during $1^{\text {st }}$ trimester of $1^{\text {st }}$ pregnancy and developed higher $1^{\text {st }}$ trimester TG levels in subsequent pregnancy were at higher risk for GDM recurrence.

These findings indicated that pregnancy itself imposes glucogenic stresses mostly through inducing insulin resistance (IR) and affection of hepatic function as evidenced by the frequency of IR and FLD among control women despite of the concomitant within normal blood glucose levels. This could be attributed to disturbed regulatory mechanisms of carbohydrate metabolism secondary to pregnancy-induced inflammatory status as previously evidenced by Giacobbe et al. [32] who found markers of chronic inflammation are associated to GDM and IR during pregnancy. Also, Tsiotra et al. [33] suggested that adipose tissue expression of adipokines contribute to increased IR and lowgrade inflammation concomitant with GDM.

As another explanation, Silva et al. [34] reported that the central and common mechanism of IR in GDM is defective signalling via $\mathrm{Akt} / \mathrm{mTOR}$ in response to insulin. On the other hand, Hill [35] attributed peripheral IR during pregnancy to increasing maternal levels of placental variant growth hormone and attributed the progressively increasing insulin levels to the expansion of maternal pancreatic $\beta$-cell mass to increase in insulin availability as a counterbalance.

The reported high frequency of women had high FLI goes in hand with multiple recent studies, where Layton et al. [30] found women with GDM had significantly higher TG, lower HDL and higher non-esterified fatty acids in comparison to women with normal glucose tolerance and Lee et al. [36] found women who developed GDM had a higher prevalence, up to $55.6 \%$, of radiological steatosis with higher FLI and hepatic steatosis index than women who did not develop GDM. Also, Correa et al. [37] detected significantly higher $1^{\text {st }}$ trimester concentrations of cholesterol, TG, insulin, LDL with increased HOMA-IR in pregnant women who subsequently developed GDM than those who did not develop GDM.

Furthermore, serum co-peptin (CP) levels estimated at the $6^{\text {th }} \mathrm{GW}$ were significantly higher in women of GDM group than in control women. These data support the previously reported association between high plasma CP levels and risk of DM $(38,39)$ that was higher in women than in men [38] and suggesting a potential role of the AVP system in the pathophysiology of diabetes and its complications [39]. In line with obtained data, $\mathrm{Ma}$ et al. [40] found high CP concentrations at the $1^{\text {st }}$ prenatal visit were associated with increased risk of GDM.

However, Ebert et al. [41] found CP level was independently associated with gestational age at blood sampling and GDM remained an independent predictor of circulating $\mathrm{CP}$ in multivariate regression analysis, but on contrary to the results of the current study and to that reported by Ma et al. [40]; Ebert et al. [41], found median serum $\mathrm{CP}$ levels were significantly lower in women with GDM than controls of cross-matched GA and BMI. However, Ebert et al. [41], failed to explain these results which are contradictory to that well-known about $\mathrm{CP}$ which is one of stress hormones [42] that is used as a marker of AVP levels and is linked to low water intake and high diabetes risk [43]. Moreover, Enhörning et al. [43] found water supplementation in habitual 
low-drinkers with high $\mathrm{CP}$ effectively lowers $\mathrm{CP}$ and FBG levels, so reducing diabetes risk

Statistical analyses of the current results defined high FLI and serum CP at the $6^{\text {th }} \mathrm{GW}$ as significant predictors for subsequent development of GDM in studied non-diabetic women who had no history of previous GDM. In line with these findings, Ma et al. [40] using the integrated discrimination improvement statistic detected significantly increased discrimination ability for $\mathrm{CP}$ levels, estimated on the $1^{\text {st }}$ antenatal visit, between women with and without GDM. Recently, Lee et al. [36] found the risk of developing GDM was positively correlated with the severity of steatosis and the relationship between FLD and GDM remained significant after adjustment for metabolic risk factors and concluded that FLD in early pregnancy is an independent risk factor for GDM.

\section{CONCLUSION}

Development of GDM is closely associated with pregnancy-induced IR and is more frequent in women had FLD. Disturbed AVP system manifested by increased serum CP levels may be concomitant event or underlying cause for GDM. Calculation of FLI at the $6^{\text {th }} \mathrm{GW}$ could discriminate women at risk for GDM later during pregnancy especially if associated with high serum CP levels. However, wider scale studies are mandatory to establish the calculated cutoff points for FLI and CP for identification of women at higher risk of GDM

\section{ACKNOWLEDGEMENTS}

The author would like to thank all staff members of Clinical Pathology department for their logistic support.

\section{REFERENCES}

[1] Abbasi A, Corpeleijn E, Meijer E, Postmus D, Gansevoort RT, Gans RO, Struck J, Hillege HL, Stolk RP, Navis G, Bakker SJ: Sex differences in the association between plasma copeptin and incident type 2 diabetes: the Prevention of Renal and Vascular Endstage Disease (PREVEND) study. Diabetologia. 2012; 55(7):1963-70.

[2] American Diabetes Association: Diagnosis and classification of diabetes mellitus. Diabetes Care. 2013; 36 Suppl 1:S67-74

[3] Andersen L, Dinesen B, Jørgensen PN, Poulsen $F$ and Røder ME: Enzyme immunoassay for intact human insulin in serum or plasma. Clinical Chemistry, 1993; 38: 578-582.
[4] Asferg CL, Andersen UB, Linneberg A, Goetze JP, Holst JJ, Jeppesen JL: Copeptin, a surrogate marker for arginine vasopressin secretion, is positively associated with glucagon. Diabet Med. 2018 Sep 22. doi: 10.1111/dme.13820. [Epub ahead of print]

[5] Bedogni G, Bellentani S, Miglioli L, Masutti F, Passalacqua M, Castiglione A, Tiribelli C. The Fatty Liver Index: a simple and accurate predictor of hepatic steatosis in the general population. BMC Gastroenterol. 2006;6:33

[6] Correa PJ, Venegas P, Palmeiro Y, Albers D, Rice G, Roa J, Cortez J, Monckeberg M, Schepeler M, Osorio E, Illanes SE: First trimester prediction of gestational diabetes mellitus using plasma biomarkers: a casecontrol study. J Perinat Med. 2019; 47(2):161168.

[7] DU HY, Jiang H, O K, Chen B, Xu LJ, Liu SP, Yi JP, He GS, Qian X: Association of Dietary Pattern during Pregnancy and Gestational Diabetes Mellitus: A Prospective Cohort Study in Northern China. Biomed Environ Sci. 2017; 30(12):887-97.

[8] Ebert T, Platz M, Kralisch S, Lossner U, Jessnitzer B, Richter J, Blüher M, Stumvoll M, Fasshauer M: Serum Levels of Copeptin are Decreased in Gestational Diabetes Mellitus. Exp Clin Endocrinol Diabetes. 2016; 124(4):257-60

[9] Enhörning S, Brunkwall L, Tasevska I, Ericson U, Tholin JP, Persson M, Lemetais G, Vanhaecke T, Dolci A, Perrier ET, Melander O: Water supplementation reduces copeptin and plasma glucose in adults with high copeptin: the $\mathrm{H} 2 \mathrm{O}$ Metabolism pilot study. J Clin Endocrinol Metab. 2018 Dec 18. doi: 10.1210/jc.2018-02195

[10] Giacobbe A, Granese R, Grasso R, Salpietro V, Corrado F, Giorgianni G, Foti G, Amadore D, Triolo O, Giunta L, Di Benedetto A: Association between maternal serum high mobility group box 1 levels and pregnancy complicated by gestational diabetes mellitus. Nutr Metab Cardiovasc Dis. 2016; 26(5):4148.

[11] Hill DJ: Placental control of metabolic adaptations in the mother for an optimal pregnancy outcome. What goes wrong in gestational diabetes? Placenta. 2018; 69:162168.

[12] Horsch A, Kang JS, Vial Y, Ehlert U, Borghini A, Marques-Vidal P, Jacobs I, Puder JJ: Stress exposure and psychological stress responses are related to glucose concentrations during pregnancy. $\mathrm{Br} \quad \mathrm{J}$ Health Psychol. 2016; 21(3):712-29.

[13] Huang $\mathrm{X}, \mathrm{Xu} \quad \mathrm{M}$, Chen $\mathrm{Y}$, Peng K, Huang Y, Wang P, Ding L, Lin L, Xu Y, Chen Y, Lu 
J, Wang W, Bi Y, Ning G: Validation of the Fatty Liver Index for Nonalcoholic Fatty Liver Disease in Middle-Aged and Elderly Chinese. Medicine (Baltimore). 2015; 94(40): e1682

[14] International association of diabetes and pregnancy study groups (IADPSG) recommendations on the diagnosis and classification of hyperglycemia in pregnancy. Diabetes Care. 2010; 33:676-682.

[15] Lacaria E, Lencioni C, Russo L, Romano M, Lemmi P, Battini L, Del Prato S, Bertolotto A, Di Cianni G: Selective screening for GDM in Italy: application and effectiveness of National Guidelines. J Matern Fetal Neonatal Med. 2015; 28(15):1842-4.

[16] Layton J, Powe C, Allard C, Battista MC, Doyon M, Bouchard L, Perron P, Wessel J, Hivert MF: Maternal lipid profile differs by gestational diabetes physiologic subtype. Metabolism. 2019; 91:39-42

[17] Lee SM, Kwak SH, Koo JN, Oh IH, Kwon JE, Kim BJ, Kim SM, Kim SY, Kim GM, Joo SK, Koo BK, Shin S, Vixay C, Norwitz ER, Park CW, Jun JK, Kim W, Park JS: Nonalcoholic fatty liver disease in the first trimester and subsequent development of gestational diabetes mellitus. Diabetologia. 2019; 62(2) :238-248.

[18] Levene AP, Goldin RD: The epidemiology, pathogenesis and histopathology of fatty liver disease. Histopathology. 2012; 61(2):141-52.

[19] Lowe LP, Metzger BE, Dyer AR, Lowe J, McCance DR, Lappin TR, Trimble ER, Coustan DR, Hadden DR, Hod M, Oats JJ, Persson B, the HAPO Study Cooperative Research Group: Hyperglycemia and Adverse Pregnancy Outcome (HAPO) Study. Associations of maternal A1C and glucose with pregnancy outcomes. Diabetes Care 2012; 35(3): 574-80.

[20] Ma HH, Yang SY, Wang P, Zhang JF: Evaluation of the value of plasma concentration of copeptin in the first prenatal visit to diagnose gestational diabetes mellitus. Acta Diabetol. 2017; 54(12):1123-1129.

[21] Matthews DR, Hosker JP, Rudenski AS, Naylor BA, Treacher DF, Turner RC: Homeostasis model assessment: insulin resistance and betacell function from fasting plasma glucose and insulin concentrations in man. Diabetologia .1985; 28:412-19.

[22] Mechanick JI, Zhao S, Garvey WT: Leptin, An Adipokine With Central Importance in the Global Obesity Problem. Glob Heart. 2017 Dec 13. pii: S2211-8160(17)30119-9.

[23] Mierzwicka A, Bolanowski M: New peptides players in metabolic disorders. Postepy Hig Med Dosw (Online). 2016; 70(0):881-6.
[24] Morgenthaler

$$
\text { NG, Struck }
$$

J, Alonso C, Bergmann A: Assay for the measurement of copeptin, a stable peptide derived from the precursor of vasopressin. Clin Chem. 2006; 52(1):112-9.

[25] Morgenthaler NG, Struck J, Jochberger S, Dünser MW: Copeptin: clinical use of a new biomarker. Trends Endocrinol Metab. 2008; 19(2):43-9.

[26] Motamed N, Sohrabi M, Ajdarkosh H, Hemmasi G, Maadi M, Sayeedian FS, Pirzad R, Abedi K, Aghapour S, Fallahnezhad M, Zamani F: Fatty liver index vs waist circumference for predicting non-alcoholic fatty liver disease. World J Gastroenterol. 2016; 22(10):3023-30.

[27] Otgonsuren M, Estep MJ, Hossain N, Younossi E, Frost S, Henry L, Hunt S, Fang Y, Goodman Z, Younossi ZM. Single non-invasive model to diagnose non-alcoholic fatty liver disease (NAFLD) and non-alcoholic steatohepatitis (NASH) J Gastroenterol Hepatol. 2014;29:20062013.

[28] Ruhl CE, Everhart JE: Fatty liver indices in the multiethnic United States National Health and Nutrition Examination Survey. Aliment Pharmacol Ther. 2015; 41(1):65-76.

[29] Sacks DA, Hadden DR, Maresh M, Deerochanawong C, Dyer AR, Metzger BE, Lowe LP, Coustan DR, Hod M, Oats JJ, Persson B, Trimble ER; HAPO Study Cooperative Research Group: Frequency of gestational diabetes mellitus at collaborating centers based on IADPSG consensus panelrecommended criteria: the Hyperglycemia and Adverse Pregnancy Outcome (HAPO) Study. Diabetes Care. 2012; 35(3):526-8.

[30] Shapiro GD, Arbuckle TE, Ashley-Martin J, Fraser WD, Fisher M, Bouchard MF, Monnier P, Morisset AS, Ettinger AS, Dodds L: Associations between maternal triclosan concentrations in early pregnancy and gestational diabetes mellitus, impaired glucose tolerance, gestational weight gain and fetal markers of metabolic function. Environ Res. 2018;161: 554-61.

[31] Sunny NE, Bril F, Cusi K: Mitochondrial Adaptation in Nonalcoholic Fatty Liver Disease: Novel Mechanisms and Treatment Strategies. Trends Endocrinol Metab. 2017; 28(4):250-260.

[32] Tsiotra PC, Halvatsiotis P, Patsouras K, Maratou E, Salamalekis G, Raptis SA, Dimitriadis G, Boutati E: Circulating adipokines and mRNA expression in adipose tissue and the placenta in women with gestational diabetes mellitus. Peptides. 2018; 101:157-166

[33] Vejrazkova D, Vcelak J, Vankova M, Lukasova $\mathrm{P}$, Bradnova O, Halkova T, Kancheva 
R, Bendlova B: Steroids and insulin resistance in pregnancy. J Steroid Biochem Mol Biol. 2014; 139:122-9.

[34] Vejrazkova D, Vankova M, Lukasova P, Vcelak J, Cirmanova V, Haluzik M, Bendlova B: Specific metabolic characteristics of women with former gestational diabetes: the importance of adipose tissue. Physiol Res. 2017; 66(Suppl. 3):S349-S356.

[35] Velho G, Ragot S, El Boustany R, Saulnier PJ, Fraty M, Mohammedi K, Fumeron F, Potier L, Marre M, Hadjadj S, Roussel R: Plasma copeptin, kidney disease, and risk for cardiovascular morbidity and mortality in two cohorts of type 2 diabetes. Cardiovasc Diabetol. 2018; 17(1):110.

[36] Villalobos-Labra R, Silva L, Subiabre M, Araos J, Salsoso R, Fuenzalida B, Sáez T, Toledo F, González M, Quezada C, Pardo F, Chiarello DI, Leiva A, Sobrevia L: Akt/mTOR Role in Human Foetoplacental Vascular Insulin Resistance in Diseases of Pregnancy. J Diabetes Res. 2017; 2017:5947859.

[37] Wang YY, Liu Y, Li C, Lin J, Liu XM, Sheng JZ, Huang HF: Frequency and risk factors for recurrent gestational diabetes mellitus in primiparous women: a case control study. BMC Endocr Disord. 2019; 19(1):22.

[38] Waters TP, Dyer AR, Scholtens DM, Dooley SL, Herer E, Lowe LP, Oats JJ, Persson B, Sacks DA, Metzger BE, Catalano PM; HAPO
Cooperative Study Research Group: Maternal and Neonatal Morbidity for Women Who Would Be Added to the Diagnosis of GDM Using IADPSG Criteria: A Secondary Analysis of the Hyperglycemia and Adverse Pregnancy Outcome Study. Diabetes Care. 2016; 39(12):2204-10.

[39] WHO. Physical status: the use and interpretation of anthropometry. Report of a WHO Expert Committee. WHO Technical Report Series 854. Geneva: World Health Organization, 1995.

[40] Wieckowska A, Feldstein AE. Diagnosis of nonalcoholic fatty liver disease: invasive versus noninvasive. Semin Liver Dis. 2008; 28:386395.

[41] Woo Baidal JA, Lavine JE: The intersection of nonalcoholic fatty liver disease and obesity. Sci Transl Med. 2016; 8(323):323rv1.

[42] Zhang Y, Lu JH, Zheng SY, Yan JH, Chen L, Liu X, Wu WZ, Wang F: Serum levels of nesfatin-1 are increased in gestational diabetes mellitus. Gynecol Endocrinol. 2017; 33(8):6214.

[43] Zhu FX, Wu HL, Tu KS, Chen JX, Zhang M, Shi C: Serum levels of copeptin are associated with type 2 diabetes and diabetic complications in Chinese population. J Diabetes Complications. 2016; 30(8):15661570

Citation: Haitham Hamza. Fatty Liver Index and Serum Copeptin as Early Predictors of Gestational Diabetes Mellitus in Non-diabetic Pregnant Women. ARC Journal of Gynecology and Obstetrics. 2019; 4(1):12-20. DOI:dx.doi.org/10.20431/2456-0561.0401003.

Copyright: (C) 2019 Authors. This is an open-access article distributed under the terms of the Creative Commons Attribution License, which permits unrestricted use, distribution, and reproduction in any medium, provided the original author and source are credited. 